\title{
Cardiac Tumors
}

\author{
Maryam Moshkani Farahani \\ Department of Echocardiography, Faculty of Medicine, \\ Baqiyatallah University of Medical Sciences, \\ Molla Sadra Avenue, Tehran
}

Iran

\section{Introduction}

Cardiac tumors are among important group of cardiovascular diseases. Early diagnosis is necessary for the best management of the tumors. There are several imaging modalities available for cardiac tumors for diagnosis including echocardiography (transthoracic echocardiography, transesophageal echocardiography, 3 dimensional echocardiography) magnetic resonance imaging (MRI) and CT scan. However, echocardiography remains the best available noninvasive tool for the diagnosis of cardiac masses, while CT and MRI provide more information about the texture and extension of tumor.

Echocardiography provides useful information about the size, texture, location, extension of tumors, hemodynamic effects on heart such as stenosis.

Cardiac tumors can be found incidentally such as myxoma or left atrial thrombus in a patient with mitral stenosis. There is also different clinical presentation for cardiac masses such as constitutional symptoms, embolic events, fever etc.

Two groups of tumors can involve the heart: primary and secondary tumors. Primary tumors are rare with a prevalence of 0.001 to 0.03 percent in autopsies (1). The majority of primary tumors are benign such as myxoma, the most common form of primary tumors, responsible for half of these tumors (2). One fourth of cardiac tumors are malignant, and sarcomas with primary cardiac lymphomas are the most common malignant primary cardiac tumors (3).

Malignant primary cardiac tumors include: angiosarcoma, rhabdomyosarcoma, osteosarcoma, myxosarcoma, fibrosarcoma and synovial sarcoma. Various sarcomas and lymphomas are the most common primary malignant cardiac tumors $(4,5)$.

Metastatic tumors are 20 to 40 times more common than primary malignant ones with prevalence of $6 \%$ in post-mortem autopsies in malignant diseases (6). The most common tumors that metastasize to heart are from lung, breast, kidney, and liver; and among tumor variety, lymphoma, melanoma and osteogenic sarcoma (2).

Malignant tumors can metastasize to heart via hematogenous spread from inferior vena cava such as renal and hepatic tumors or via metastatic formation by systemic tumors such 
as malignant melanoma, lymphomas, leukaemias and sarcomas. Lymphatics and direct invasion from adjacent organs such as lung and breast cancers or mediastinal lymphomas is another way of spread $(7,6)$.

\section{Benign primary cardiac tumors}

\subsection{Myxoma}

Three quarters of all primary cardiac tumors are benign and half of them are myxomas. These tumors occur mostly in third decade or later. Myxomas can occur as an isolated tumor in left atrium (the most common site of this tumor)[figure 1] or as familial form (Carney syndrome) which is associated with other manifestations. Most frequently it occurs in left atrium, then in right atrium, right ventricle and left ventricle; it can infrequently involve the valves. It is mostly attached to fossa ovalis via its stalk.

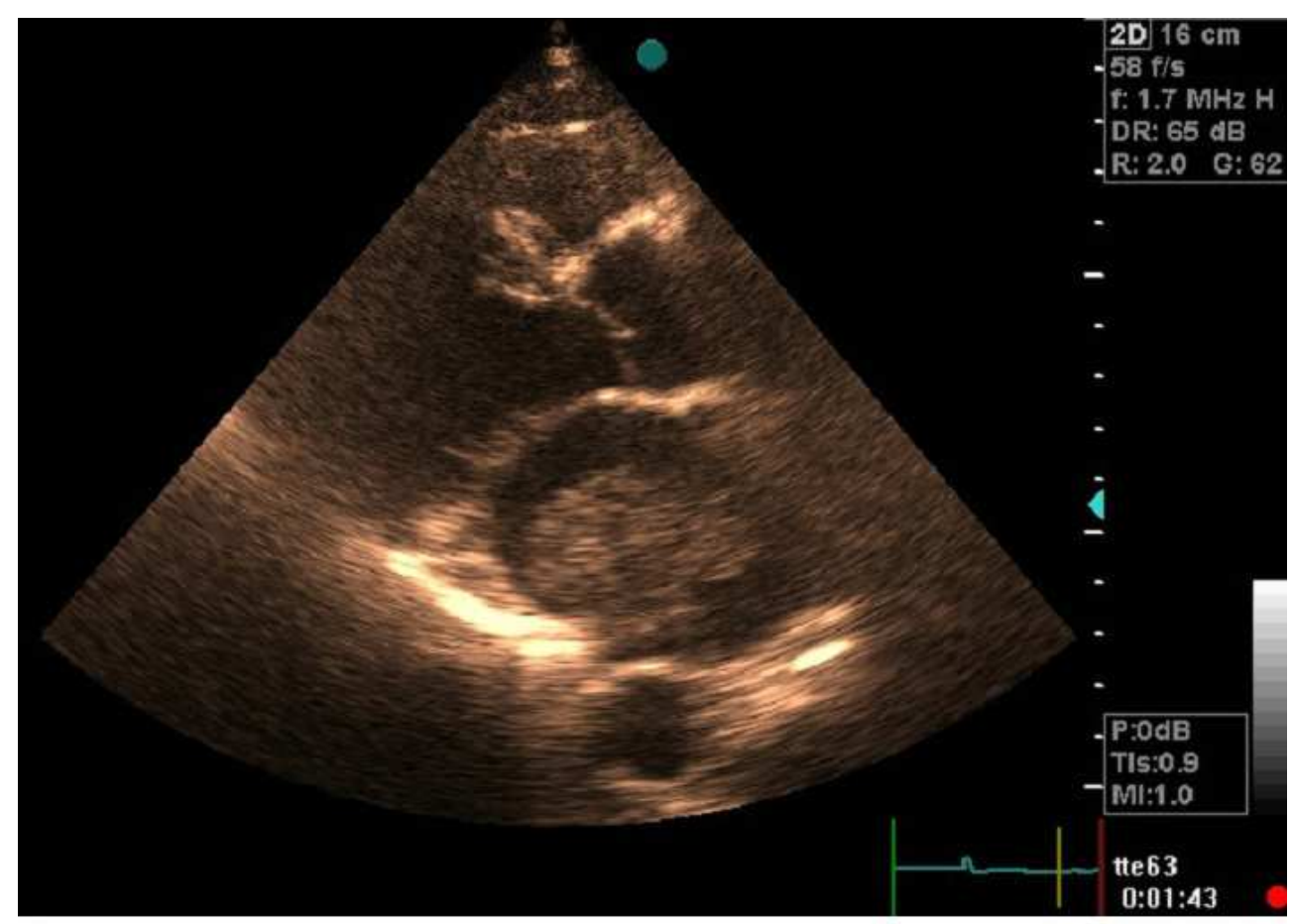

Fig. 1. Parasternal long axis view. A 38 year old man with history of dyspnea.

Echocardiography revealed left atrial mass. He underwent cardiac surgery and pathology showed myxoma.

Myxoma has different clinical presentations. These include constitutional symptoms such as fever, weight loss, embolic events and symptoms of valvular obstruction such as the symptoms of mitral valve stenosis (figure 2). 


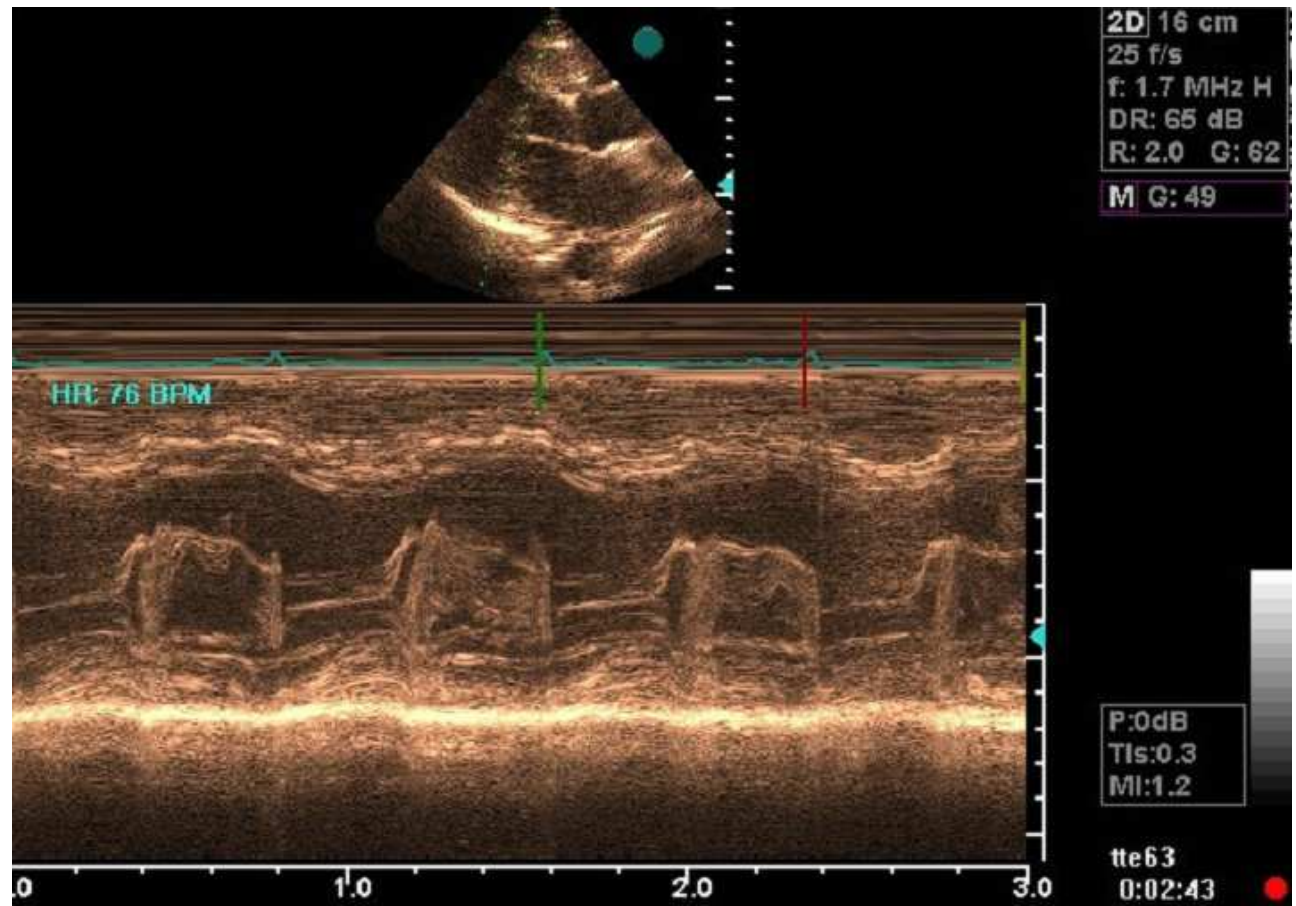

Fig. 2. A 38 year old man with history of dyspnea. Myxoma can protrude through mitral valve and in M-mode mitral stenosis can be visualized as seen in this Echocardiograph. 
It has also different shapes as rounded or polypoid with narrow stalk and attachment to interatrial septum or fossa ovalis. The mass is mostly homogenous; however, small scattered area of calcification may be seen. Mobile particles of this tumor describe and predict its tendency for embolic events (8).

Echocardiography provides useful information about the location, size, extension and texture of this tumor, and one should be careful not to miss the multiple myxomas that could be found in other chambers.

Definite treatment for myxoma is total excision of the mass. Follow up echocardiography to rule out recurrence is recommended.

\subsection{Papillary fibroelastoma}

Papillary fibroelastoma is a rare, primary benign cardiac tumor that is most frequently found in the cardiac valves (9). It is the third primary cardiac tumor after myxoma and lipoma. These tumors are mostly found incidentally on post mortem. However, because of high tendency for systemic emboli, prompt diagnosis and management is necessary. Other rare presentations such as sudden death have been reported (10-12).

Papillary fibroelastoma represents $7.9 \%$ of benign primary cardiac tumor in adults (9). Approximately $90 \%$ of primary fibroelastomas arise from valves on ventricular side of pulmonary and aortic valve and atrial side of mitral and tricuspid valve (13-14). Aortic or mitral valves are mostly affected (15-16). The tricuspid valve is most affected in children; however, mitral and aortic valves are mostly affected in adults (17). Echocardiography remains the main tool for detection of this tumor. Because of involvement of cardiac valves other diagnosis such as infective endocarditis, degenerative changes and OLamble's excrescences should be kept in mind. Typical echocardiographic features include round, oval or irregular appearance, with a homogenous texture with small stalk (18). Surgical removal is indicated for large mobile tumors.

\subsection{Rhabdomyoma}

It is the most frequent cardiac tumor of childhood (about $60 \%$ of cardiac tumors) which is frequently found by fetal echocardiography (8). This tumor occurs in both ventricles equally with intramural involvement; however, atrioventricular valves involvement is also seen. This tumor may regress spontaneously.

\subsection{Lipoma}

It is a benign cardiac tumor that is asymptomatic in many patients (3). CT scan or MRI can easily define the tissue characteristic of fat and make an accurate diagnosis.

\subsection{Hemangioma}

It is a benign vascular tumor which occurs equally in left and right ventricles, and in right atrium. When tumor is resectable, total excision is recommended. Other benign cardiac tumors include cardiac paraganglioma (8) and fibroma. 


\section{Malignant primary cardiac tumors}

Sarcomas are the most common primary malignant tumors and consist of $95 \%$ of cases. Any part of heart can be affected and rapid progression of disease is the usual clinical course of this tumor (8).

\subsection{Angiosarcoma}

Angiosarcoma is the most common primary malignant cardiac tumor (7). Men are involved more than female with a ratio of 2:1. Its usual location is right atrium and interatrial septum with involvement of pericardium and pericardial effusion [figure 3] (8). Other forms of sarcoma can occur in the left side of the heart and resemble the presentation of myxoma. It has a poor prognosis.

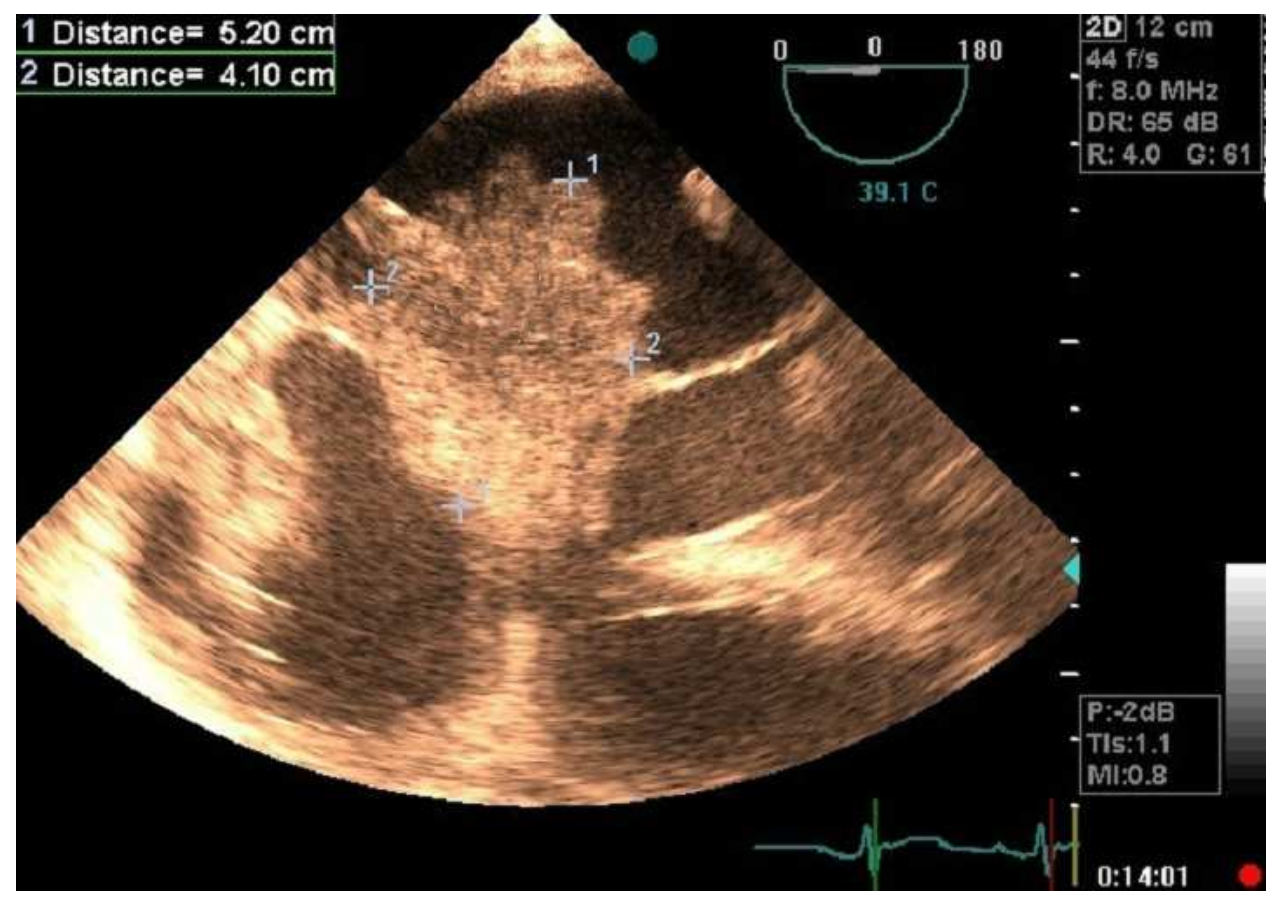

Fig. 3. Large tumor in right atrium with invasion toward interatrial septum and left atrium with pericardial effusion. In a 27 year old man who presented with progressive dyspnea.

\section{Metastatic cardiac tumors}

Metastatic tumors are 20 to 40 times more common than primary malignant ones with prevalence of $6 \%$ in post-mortem autopsies in malignant diseases (6).

\subsection{Malignant melanoma}

For the first time the term "melanotic heart" was introduced by William Norris in 1820 (7). However, many cases of malignant melanoma have been described in scientific literature. 
Malignant melanoma frequently (50-71\%) metastasizes to the heart (19). It seems to have the highest rate of metastases to heart. When a patient presents with cardiac metastases of melanoma, the disease has already spread throughout the body and is rarely curable (20). Single metastasis is rare. Metastases could be found in right side or left side; however, bilateral metastasis is frequently seen (21). The way of tumor spread toward heart is mostly hematogenous as seen in lymphoma and leukemia.

Previously, histologic diagnosis of malignant melanoma was made postmortem; however, with early detection of metastases due to availability of new imaging modalities, definite antemortem diagnosis and pathologic examination is frequently possible. Tissue specimen can be obtained by echocardiography guided transvenous biopsy or by resection of mass (22).

The symptoms are nonspecific such as chronic pericarditis, congestive heart failure, pericardial effusion, tamponade, conduction disturbances or defects, arrhythmias such as ventricular or supraventricular heart rhythm disturbances $(23,24)$, syncope, embolism events such as transient ischemic attack and hemodynamic changes secondary to valve dysfunction.

Malignant melanoma has the highest rate of metastases to heart; however, due to improvement in treatment for this disease, longer survival than previous is now possible (25) and with newer imaging modalities early detection of metastases is possible and the physician should be alert of the risk of metastases. Transesophageal echocardiography has higher sensitivity than transthoracic echocardiography and cardiac magnetic resonance imaging with its ability to define the mediastinal involvement could also be used. According to tumor characteristics, its burden, location and size, palliative surgery or complete resection or adjuvant systemic therapy is recommended.

\section{Summary}

Echocardiography both transthoracic echocardiography (TTE), transesophageal echocardiography (TEE), is the commonly available noninvasive method for the diagnosis of cardiac masses. Tumor size, location and texture, and its extension to adjacent organs, its attachment to cardiac structures, presence or absence of pericardial effusion, interference with valve function, any obstruction and tumor mobility could be evaluated by echocardiography. In patients with poor echo window, TEE gives superior results, however, in some patients for better evaluation of cardiac tumor and its extension, other imaging modalities such as MRI is needed. Extra cardiac structures could be visualized better in TTE then TEE which is important for surgeons for choosing the most suitable plan for surgery(7).

\section{Acknowledgement}

Special thanks to doctor Hyderi for his valuable comments.

\section{References}

[1] Reynen K. Frequency of primary tumors of the heart. Am J Cardiol 1996;77: 107.

[2] Reynen K. Cardiac myxomas. N Engl J Med 1995; 333: 1610-1617. 
[3] Libby P, Bonow R, Mann DL, Zipes DP. Braunwald's Heart Disease: A Textbook of Cardiovascular Medicine, 8th edition

[4] Roberts WC, Glancy DL, DeVita VT. Heart in malignant lymphoma. A study of 196 autopsy cases. Am J Cardiol 1968;22: 85-107

[5] Silverman J, Olwin JS, Graettinger JS. Cardiac myxomas with systemic embolization review of the literature and report of a case. Circulation 1962; 26: 99-10

[6] Hoffmann U, Globits S, Frank H, Cardiac and paracardiac masses Current opinion on diagnostic evaluation by magnetic resonance imaging . Eur Heart J (1998) 19, 553 563.

[7] McAllister Jr HA, Fenoglio Jr JJ. Tumors of the cardiovascular system. Atlas of tumor pathology, 2nd series. Fascicle 15 Washington, D. C. Armed Forces Institute of Pathology, 1978:1-20.

[8] Otto CM. The Practice of Clinical Echocardiography. 3rd edition. 2008, pp. 1108-1131.

[9] Edwards FH, Hale D, Cohen A, et al: Primary cardiac valve tumors. Ann Thoracic Surg 1991; 52:1127-31.

[10] Klarich KW, Enriquez Sarano M, Gura GM, Edwards WD, Tajik AJ, Seward JB. Papillary fibroelastoma:Echocardiographic Characteristics for diagnosis and pathologic correlation Am Coll Cardiol 1997;30:784-790.

[11] Mugge A, Daniel WG, Haverich A, et al: Diagnosis of non-infective cardiac mss lesions by two-dimensional echocardiography. Comparison of the transthoracic and transesophageal approaches. Circulation 1991; 83:70-78.

[12] Winkler M, Higgins CB: Suspected intracardiac masses: Evaluation with MR imaging. Radiol 1987; 165:117-122.

[13] Sun JP, Ashe CR, Yang XS, Cheng GG, Scalia GM, Massed AG, Griffin BP, Ratlift NB, Stewart WJ, Thomas JD. Clinical and echocardiographic characteristics of papillary fibroelastoma : a retrospective and prospective study in 162 patients. Circulation 2001;103:2687-93.

[14] Lichtenstein HL, Lee JC, Stewart S. Papillary tumor of the heart:incidental finding at surgery. Hum pathol 1979;10:473-5.

[15] Mc Alister HA, Fenoglio JJ. Tumors of the cardiovascular system. In: Atrak of tumor pathology second series fascicle 15. Washington DC Armed Forces Institute of pathology, 1978; 20-25.

[16] Roberts WC, Papillary Fibroelastoma of the heart. Am J Cardiol 1997; 80:973-975.

[17] Hicks KA, Kovach JA, Frishberg DP, Wiley TM, Gurezak PB, Vernalis MN. Echocardiographic evaluation of papillary fibroelastoma: a case report and review of the literature. Am J Soc Echocardiogr 1996;9:353-60

[18] Almagro UA, Perry LS, Choi H, Pinator K. Papillary fibroelastoma of the heart. Report of six cases. Arch Pathol Lab Med. 1982;106:318-321

[19] latt EC, Heiz DR, Cardiac Metastases. Cancer 1990;65:1456-9

[20] Chen $\mathrm{RH}$, Gaos CM, Frazier OH. Complete resection of a right atrial intracavitary metastatic melanoma. Annals thoracic surgery 1996;61:1255-7

[21] Reynen K, Köckeritz U, Strasser R. H. Metastases to the heart Annals of Oncology 2004;15:375-381.

[22] Rubin DC, Ziskind AA, Hawke MW, Plotnick GD. Transesophageal echocardiographically guided percutaneous biopsy of a right atrial mass. Am Heart J 1994;127:935-6. 
[23] Lin TK, Stech JM, Eckert WG, Liu JJ et al. Pericardial angiosarcomata simulating pericardial effusion by echography. Chest 1978; 73: 881-3.

[24] Coghlan JG, Paul VE, Mitchell AG. Cardiac involvement by lymphoma. Diagnostic difficulties. Eur Heart J 1989; 10:765-8

[25] Samiei N, Moshkani Farahani M, Sadeghipour A, Mozaffari K, Maleki M. Intracardiac metastasis of malignant melanoma. European Journal of Echocardiography (2008) 9, 393-394. 


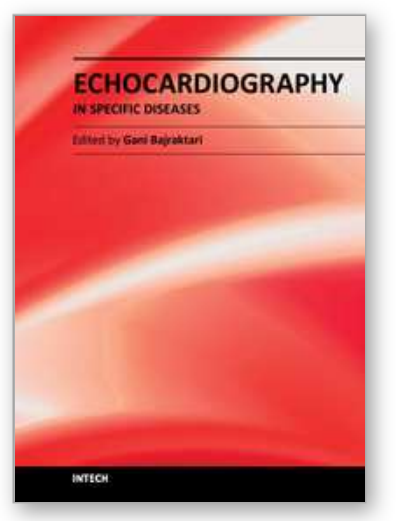

\author{
Echocardiography - In Specific Diseases \\ Edited by Prof. Gani Bajraktari
}

ISBN 978-953-307-977-6

Hard cover, 160 pages

Publisher InTech

Published online 18, January, 2012

Published in print edition January, 2012

The book "Echocardiography - In Specific Diseases" brings together contributions from well- known researchers from around the world, some of them specialized in imaging science in their clinical orientation, but also representatives from academic medical centers. Each chapter is structured and written to be accessible to those with a basic knowledge of echocardiography but also to be stimulating and informative to experts and researchers in the field of echocardiography. This book is primarily aimed at cardiology fellows during their basic echocardiography rotation, fellows of internal medicine, radiology and emergency medicine, but also experts in echocardiography. During the past few decades technological advancements in echocardiography have been developing rapidly, leading to improved echocardiographic imaging using new techniques. The authors of this book tried to explain the role of echocardiography in several special pathologies, which the readers may find in different chapters of the book.

\title{
How to reference
}

In order to correctly reference this scholarly work, feel free to copy and paste the following:

Maryam Moshkani Farahani (2012). Cardiac Tumors, Echocardiography - In Specific Diseases, Prof. Gani Bajraktari (Ed.), ISBN: 978-953-307-977-6, InTech, Available from:

http://www.intechopen.com/books/echocardiography-in-specific-diseases/cardiac-tumors

\section{INTECH}

open science | open minds

\author{
InTech Europe \\ University Campus STeP Ri \\ Slavka Krautzeka 83/A \\ 51000 Rijeka, Croatia \\ Phone: +385 (51) 770447 \\ Fax: +385 (51) 686166 \\ www.intechopen.com
}

\author{
InTech China \\ Unit 405, Office Block, Hotel Equatorial Shanghai \\ No.65, Yan An Road (West), Shanghai, 200040, China \\ 中国上海市延安西路65号上海国际贵都大饭店办公楼405单元 \\ Phone: +86-21-62489820 \\ Fax: +86-21-62489821
}


(C) 2012 The Author(s). Licensee IntechOpen. This is an open access article distributed under the terms of the Creative Commons Attribution 3.0 License, which permits unrestricted use, distribution, and reproduction in any medium, provided the original work is properly cited. 